\title{
'n Belangrike besluit oor kanselruil tussen die drie Afrikaanse kerke deur die Algemene Kerkvergadering van die Nederduitsch Hervormde Kerk in 1894
}

S J Botha

\section{ABSTRACT}

An important decision in 1894 by the General Assembly of the Nederduitsch Hervormde Kerk on the "exchange of pulpits" between the three Afrikaans-speaking churches

The General Assembly of the Nederduitsch Hervormde Kerk decided in 1894 to correspond with the other two churches in view of reaching an agreement on the matter "exchange of pulpits" between the churches. The background and meaning of this decision for the Nederduitsch Hervormde Kerk in its relation to the other two churches is discussed.

\section{INLEIDEND}

Carl Borchardt het op 1 Februarie 1974 voor die kongres van die Kerkhistoriese Werkgemeenskap van Suid-Afrika 'n voordrag gelewer onder die titel "Die betrekkinge tussen die drie Afrikaanse Kerke 1886-1973" bedoeling was om aan te toon "hoe die kerke deur die jare met mekaar in verbinding getree het om oor hulle onderlinge verskille te praat en mekaar amptelik te erken" 2 . In sy voordrag het hy verwys na 'n besluit van die Algemene Kerkvergadering van die Nederduitsch Hervormde Kerk in 1894 "om met die ander twee Hollandse Protestantse susterkerke te korrespondeer oor die moontlikheid om tot 'n broederlike verhouding te kom in sake oor en weer preek deur predikante" 3 .

As bydrae ter huldiging van Carl Borchardt by sy aftrede as hoogleraar, word in hierdie artikel kortliks nader ingegaan op hierdie genoemde besluit. Vir die Nederduitsch Hervormde Kerk was hierdie besluit van groot belang omdat die bepaalde beskouing oor die betewing van die eenheid van die kerk soos dit in die Nederduitsch Hervormde Kerk verstaan is en steeds verstaan word, daarin na vore gekom het. Daarom kan dit tog van betekenis wees in die gesprek tussen die drie kerke om vir 'n oomblik na die agtergrond en bedoeling van hierdie besluit te kyk. 
Op die Algemene Kerkvergadering van 1894 het 'n kommissie wat daartoe benoem was "om een regel daar te stellen in hoe verre in onze Kerken over en weder gepredikt kan worden door de predikanten der Hollandsche Zusterkerken in deze Republiek, Kaapkolonie, Vrijstaat en Natal" verslag gedoen. Die kommissie het die Algemene Kerkvergadering versoek om die volgende vier aanbevelings te oorweeg:

"1 Dat uwe Commissie het vooralsnag niet raadzaam acht zulk een regel vast te stellen voor en aleer de verschillende gemeenten over deze zoo belangrike zaak gehoord zijn.

2 Echter doordrongen van den wensch om van onze zijde te trachten alle mogelijke middelen ter hand te nemen om met onze Zusterkerken in broederlijke liefde samen te leven, oveenkomstig de bevelen van onzen Heiland ons in zijn dierbaar woord geopenbaard; uwe vergadering aanbevelen aan de verschillende Kerkeraden op te dragen, de gevoelens hunner respectieve gemeenten hierover te hooren, en bij de eerst volgende Algemeene Kerkvergadering rapport te doen.

3. De Commissie van de Algemeene Kerkvergadering te machtigen in correspondentie te treden met de twee Hollandsche Protestantsche Zusterkerken in deze Republiek alsmede met de Hollandsch Protestantsche Kerken binnen Zuid Afrika, in hoeverre het mogelijk zal kunnen zijn om tot een broederlijke verhouding te komen in zake het over en weer prediken van predikanten.

4 Van al hare handelingen bij de volgende Algemeene Vergadering rapport te doen" 4 .

Al vier hierdie aanbevelings is eenparig deur die Algemene Kerkvergadering aanvaar. Hoewel die Algemene Kerkvergadering die aanbeveling van die kommissie tot versigtigheid aanvaar het, is die aanbeveling wat spreek van die dringende en ernstige wens tot nouer skakeling tussen die kerke net so eenparig ondersteun. Trouens, dit is as 'n opdrag van Jesus Christus gesien dat daar ' $n$ verhouding van broederlike liefde tussen die kerke moes bestaan. Sonder dat na spesifieke Skrifgedeeltes verwys word, word gestel dat dit "bevelen van onzen Heiland ons in zijn dierbaar woord geopen- 
baard" is. Dit dui daarop dat daar besliste konsensus oor hierdie aangeleentheid onder die afgevaardigdes op die vergadering was waaruit ook weer afgelei kan word dat in die Kerk self ook oor die saak nie noemenswaardige verskille kon bestaan nie.

Organisatoriese geskeidenheid verhoed nie eenheid en uitdrukking van eenheid nie. As die besondere omstandighede waarin die Nederduitsch Hervormde Kerk in 1894 verkeer het in aanmerking geneem word, dan moet hierdie besluit aan die een kant as merkwaardig aangeteken word. Dit word selfs merkwaardiger as bedink word dat dit eenparig geskied het. Tog is dit andersyds nie so 'n merkwaardige besluit nie, omdat hierdie besluit volkome in lyn gelê het met en voortsetting was van die houding, gesindheid en tradisie van die Kerk in verband met die saak.

\section{DIE VERHOUDING TUSSEN DIE AFRIKAANSE KERKE IN 1894}

Tussen die Nederduitsch Hervormde Kerk en die Gereformeerde Kerk was daar teen 1894 'n min of meer stabiele verhouding van begrip en waardering. Die kerkskeuring wat in 1859 deur die afskeiding onder ds Dirk Postma plaasgevind het en gelei het tot die stigting van die (enkel) Gereformeerde $\mathrm{Kerk}^{5}$ het reeds vyf-en-dertig jaar in die verlede gelê en niks besonders het in die tyd gebeur wat die verhouding tussen die twee kerke onder verdere spanning geplaas het nie ${ }^{6}$. Van kanselruil was daar egter hoegenaamd geen sprake nie.

Tussen die Nederduitsch Hervormde Kerk en die Nederduitsch Hervormde of Gereformeerde Kerk, die derde "Zusterkerk" wat in gedagte was, was die saak egter totaal anders. Om die minste daarvan te sê was daar 'n gespanne en selfs emosiebelaaide atmosfeer tussen die twee kerke. Die oorsakk hiervan was, hoe ironies en tragies dit ookal mag wees, die poging tot kerkvereniging van 1885 tussen die Nederduitsch Hervormde Kerk, die ou staatskerk van die Zuid-Afrikansche Republiek, en die Nederduitsch Gereformeerde Kerk wat in 1865 van die Neder-duitsch Hervormde Kerk onder ds F Lion Cachet afgeskei het?

Aangesien die kerkvereniging van 1885 al meermale uitvoerig behandel is ${ }^{8}$ word hier terwille van die volledige konteks, volstaan met slegs enkele opmerkings. Die drang tot kerkvereniging het sy oorsprong gehad op die nasionaal-politieke terrein, waar die Eerste Vryheidsoorlog (1880-1881) 'n lewenskragtige eenheidstrewe en samehorigheidsgevoel wakker gemaak het, nie net onder die republikeinse Afrikaners van die Oranje-Vrystaat en Transvaal nie, maar selfs onder die koloniale 
Afrikaners van die Kaap. In Transvaal het die sterk nasionaal-politieke strewe veral op kerklike terrein 'n belangwekkende nawerking gehad waar dit gelei het tot 'n strewe na kerklike eenheid deur kerkvereniging. So sterk was die politieke eenheidsgevoel dat die kerkvereniging beplan en uitgevoer is ten spyte van bedenklike gesindhede tussen die deelnemende partye. Bowendien is die vereniging deurgevoer op 'n wyse wat spreek van argeloosheid en oppervlakkigheid, waar die motivering nie op suiwer Bybels-kerklike gronde berus het nie en die oë gesluit is vir wesenlike en diepgaande verskille tussen die deelnemende partye. Noodsaaklike voorafgaande dieptestudie oor tersaaklike teologiese en kerkregtelike aangeleenthede is nie onderneem nie. Dit was asof die twee deelnemende kerke eenvoudig doof en blind geword het vir enigiets wat op enige wyse in die weg van die begeerde vereniging sou kon staan. Selfs goedbedoelde vermanings tot versigtigheid uit die mond van volksleiers soos Paul Kruger, is eenvoudig geïgnoreer ${ }^{9}$.

Die gevolg was dat minstens 'n derde van die Nederduitsch Hervormde Kerk se lidmate nooit verenig het nie, maar onder leiding van veral die Konsulentsgemeente van Pretoria ${ }^{10}$ die Nederduitsch Hervormde Kerk gehandhaaf het ${ }^{11}$. Na die vasstelling van die naam van die verenigde kerk as Nederduitsch Hervormde of Gereformeerde Kerk in 1889 het nog 'n verdere minstens een derde van die lidmate wat wel verenig het, georganiseerd onder leiding van die Prokurasiekommissie uit die verenigde kerk getree om na die Nederduitsch Hervormde Kerk terug te keer ${ }^{12}$.

Onder hulle het selfs vier volledige selfstandige gemeentes getel, naamlik Potchefstroom, Ventersdorp, Wakkerstroom en Pretoria ${ }^{13}$. Bowendien het reeds kort na die vereniging van 1885 van die lidmate van die Nederduitsch Hervormde Kerk wat wel verenig het, individueel of as gesinne of kleiner groepe na die Nederduitsch Hervormde Kerk teruggekeer $^{14}$.

In sy proefskrif konkludeer S P Pretorius dat daar minstens agt hoofredes was waarom die kerkvereniging misluk het, naamlik ${ }^{15}$ :

1 die nasionaal-politieke dryfveer in plaas van 'n kerklik-teologiese motivering;

2 die feit dat al die onderhandelinge slegs op sinodale vlak gevoer is en die gemeentes nooit geraadpleeg is nie;

3 die argelose wyse van optrede van die Algemene Kerkvergadering van die Nederduitsch Hervormde Kerk tydens onderhandelinge;

4 die houding en optrede van die Algemene Kerkvergadering en die verenigingskommissie van die Nederduitsch Gereformeerde Kerk; 
die teologiese verskille tussen die twee kerke waaraan tydens die onderhandelinge hoegenaamd geen aandag gegee is nie;

die uiteindelike vasstelling van die naam van die verenigde kerk;

7 die onkerkregtelike optrede van die eerste Algemene Kerkvergadering van die verenigde kerk teenoor die Konsulentsgemeente van Pretoria; en laastens

8 die verskil in opvatting of die vereniging van die begin af ' $n$ "nuwe" kerk daargestel het en of dit voorlopig was.

Feitlik al agt hierdie redes het geweldige sterk emosies losgemaak wat die verhouding tussen die kerke vertroebel het en so gespanne gemaak het as wat dit ooit kon wees. Hierdie emosies en spanning is baie sterk verhewig deur faktore soos die stryd oor die kerklike eiendomme en 'n hewige getwis in die koerante waaraan lidmate en ampsdraers van beide kante deelgeneem het en waarin bitter woorde, verwyte en beskuldigings oor en weer geslinger is. Engelbrecht merk oor hierdie koerantgetwis op: "Dit was gewoonlik van weerskante van 'n haatlike en persoonlike aard sonder die minste Christelike gees" 16 .

Die stryd oor die kerklike eiendomme kon ook nie, selfs nie deur bemiddelingspogings van president Kruger minlik geskik word nie en is na die hooggeregshof vir beslegting geneem ${ }^{17}$. Selfs die hofuitspraak van 5 Junie 1893 ten gunste van die Nederduitsch Hervormde Gemeente Standerton (Trichardtsfontein) wat as toetssaak gedien het, het nie die spanning en emosies ontlont nie ${ }^{18}$. Vir die Nederduitsch Hervormde Kerk het die hofuitspraak groter sekuriteit ten opsigte van eiendomme gebring en is die weg ook gebaan dat 'n "vereniging" kon plaasvind tussen die deel van die Nederduitsch Hervormde Kerk wat nooit verenig het nie en die gemeentes wat onder leiding van die Prokurasiekommissie uit die verenigde kerk uitgetree het ${ }^{19}$. Dit het wel 'n dempende invloed gehad op die gespanne emosies binne die Kerk. Dit het egter nie die gespanne verhouding totaal weggeneem nie, want dit was ook nie die einde van alle hofgedinge oor die eiendomme nie.

Vir die Nederduitsch Hervormde of Gereformeerde Kerk was die hofuitspraak wel 'n groot teleurstelling wat emosies in die kerk opgejaag het. Aan die regering is ' $n$ brief gerig om inligting te gee oor die "dreigende toestand" in die kerk en is onder andere gestel: "dat die thans bestaande Hervormde Kerk in geenen dele als een wettig lichaam met zuivere en billike rechten beschouwd kan worden, maar wel dat dat genootschap zijn ontstaan en voortbestaan aan een geest van scheuring en willekeur te danken, heeft" ${ }^{20}$. Hierdie houding en optrede was in die 
Nederduitsch Hervormde Kerk bekend.

Alles bymekaar genome het die poging tot kerkvereniging van 1885 nie daarin geslaag om totale eenheid of selfs net groter eenheid op die kerklike werf in die Zuid Afrikaansche Republiek te bewerk nie. Daar was steeds drie kerke en as die verhouding voor die kerkvereniging tussen die Nederduitsch Hervormde Kerk en die Nederduitsch Gereformeerde Kerk veel wense oorgelaat het, dan was dit na die vereniging veel erger.

'n Besluit ten opsigte van kanselruil onder sulke negatiewe omstandighede moet inderdaad as merkwaardig aangemerk word.

Dit is duidelik dat ten spyte van die groter hoeveelheid negatiewe faktore wat sterk middelpuntvliedende kragte opgewek het, die Nederduitsch Hervormde Kerk se besluit oor kanselruil in 1894 toon dat by die Kerk 'n duidelike besef van die geloofseenheid tussen die kerke was wat sterker was as die feit van organisatoriese geskeidenheid en as diepgaande verskille en pynlike gebeure.

\section{DIE TRADISIE VAN DIE NEDERDUITSCH HERVORMDE KERK}

Hoewel hierdie besluit in die bepaalde situasie inderdaad merkwaardig is vanweë die spanningsvolle en emosiebelaaide atmosfeer soos aangetoon, lê die besluit tog presies in lyn met die tradisie wat tot op daardie stadium deur die Kerk ten opsigte van die verhouding met die ander kerke gevolg is. Vanaf die vestiging in Transvaal, aanvanklik as losstaande gemeentes, was dit die geval. Besoekende predikante uit die Kaapse kerk is verwelkom en toegelaat om te preek ${ }^{21}$. Met die totstandkoming van 'n sinodale vergadering in 1853 vir hierdie gemeentes, is hierdie gebruik ook amptelik bevestig. Want hoewel by die geleentheid amptelik ' $n$ besluit geneem is om inlywing by die Kaapse Sinode te verwerp en die bestaan as 'n selfstandige en onafhanklike kerk wat sedert die aanvang van die Groot Trek bestaan het, te handhaaf ${ }^{22}$, is daar tog besluit om met die Kaapse kerke "ofschoon onafhankelijk een band van vereeniging" 23 te handhaaf. Hierdie "band van vereeniging" het, soos ds Dirk van der Hoff dit gestel het, beteken dat in ooreenstemming met Efesiërs 4:3 "ons benaarstigen om te behouden de eenheid des geestes, door den band des vredes" opgetree sou word 24 . Daarom is die wens ook uitgespreek dat " $\mathrm{W}_{\mathrm{ij}}$ hartelijk in eene geregelde briefwisseling met elkander te komen..., waarin wij de toestand en de behoeften onzer kerk, hare zedelijke en godsdienstige ontwikkeling kenbaar maken, en met u spreken zullen van onze hope in Christus, en zoo alles wat ons in het godsdienstige en zedelijke op het hart ligt of der 
mededeling waardig is; opdat ook onder ons de gemeenschap der heiligen eene waarheid worden moge" 25 .

Dit was duidelik dat terwyl die reeds bestaande selfstandigheid en onafhanklikheid gehandhaaf is, die eenheid in geloof erken en die broederhand uitgesteek is ${ }^{26}$. In die praktyk het dit beteken dat besoekende predikante en proponente uit die Kaapse kerk gereeld genooi is om van Hervormde kansels af te preek. Dit het in 1856 met di J H Neethling van Prins Albert en A A Louw van Fauresmith gebeur ${ }^{27}$.

Hierbenewens is verskeie predikante uit die Kaapse kerk asook proponente wat hulle opleiding aan die Stellenbosse Kweekskool deurloop het na Hervormde Gemeentes beroep soos ds $\mathrm{J} C$ de Vries na Zeerust ${ }^{28}$, prop D P Ackerman na Wakkerstroom ${ }^{29}$ en prop H S Bosman na Pretoria ${ }^{30}$.

Dit was egter ook nie net predikante uit die Kaapse kerk wat tot die preekstoel van Hervormde gemeentes uitgenooi is nie. So het ds Dirk Postma van die Afgeskeie Gereformeerde Kerk in Nederland voor die afskeiding van die Gereformeerde Kerk in 1859 in Transvaal in sowel die gemeente Potchefstroom as Rustenburg preekbeurte waargeneem ${ }^{31}$.

Daar was dus ' $n$ duidelike tradisie oor die eenheid van die kerk en die praktiese betoning van die eenheid binne die Nederduitsch Hervormde Kerk. Dit het onder andere kanselruil ingesluit en dit is wel deeglik deur die Kerk in praktyk gebring. Die bitterheid en onaangenaamheid wat die mislukte kerkvereniging omgewe het, kon hierdie tradisie, begryplikerwys, onder geweldige druk plaas en dit dalk in 'n ander koers laat beweeg het. Dit het egter nie gebeur nie. Die rede hiervoor moet gesoek word, nie alleen in die feit dat dit 'n beginselstandpunt vir die Nederduitsch Hervormde Kerk was nie, maar ook die leidinggewende figure in die Kerk wat ten spyte van moeilike omstandighede gebalanseerde en oorwoë leiding gegee het. Dit was by uitnemendheid die geval met die enigste predikant van die Nederduitsch Hervormde Kerk, ds M J Goddefroy.

\section{DIE HOUDING VAN DS GODDEFROY TEENOOR DIE NEDERDUITSCH HERVORMDE OF GEREFORMEERDE KERK}

Goddefroy as die belangrikste leidinggewer in die Nederduitsch Hervormde Kerk, se houding en gesindheid sou sekerlik bepalend wees vir die toekomstige verhouding tussen die kerke en dan veral tussen die Nederduitsch Hervormde Kerk en die nuwe Nederduitsch Hervormde of Gereformeerde Kerk, die verenigde kerk. Indien hy 'n ongenaakbare of veglustige houding sou ingeneem het, sou hy daarmee alleen die twiste hewiger laat 
opvlam en die stryd laat vererger het. Gelukkig het hy dit besef en was hy ervare genoeg om by die bekende tradisie binne die Kerk in verband met die verhouding tot die ander kerke aan te sluit en die gemoedere binne die Nederduitsch Hervormde Kerk te kalmeer.

Van die begin af was dit sy houding dat die goeie reg van bestaan van die Hervormde Kerk onwrikbaar gehandhaaf moes word, terwyl terselfdertyd die broederhand na die ander kerk uitgesteek moes word en die eenheid in geloof erken moes word. Dit was vandat hy in 1887 uit Nederland in die Zuid-Afrikaansche Republiek aangekom het sy houding en standpunt en dit het ook 'n bepalende rol gespeel in die byna bomenslike taak van reorganisasie en heropbou wat hy in die totaal ontwrigte Nederduitsch Hervormde Kerk moes verrig ${ }^{32}$.

Reeds by die eerste Algemene Kerkvergadering na die mislukte vereniging in Februarie 1888, minder as ' $n$ jaar na sy aankoms in die ZuidAfrikaansche Republiek, het hy baie duidelik in die rigting leiding gegee. By die opening het hy Johannes 17 gelees en na aanleiding van verse 21-23 'n kort openingsrede gelewer ${ }^{33}$. Ongelukkig is die rede nie opgeteken nie, wat dit moeilik maak om presies te kan bepaal hoe sy gedagtes geloop het. Uit enkele opmerkings aan die einde van die Vergadering asook uit sy geskrif De Kerkkwestie, niet een leer- maar een lewenskwestie van 1890 kan tog wel die afleiding gemaak word dat die betrokke verse nie vir hom uiterlike of organisatoriese eenheid dwingend gemaak het nie, terwyl die gebod tot innerlike eenheid, eenheid in geloof wel daarin opgesluit lê.

Aan die einde van die Vergadering het hy opgemerk:

"Daarom is ons, hoewel wij naar eenheid streven, de eenheid die ons van de andere zijde werd aangeboden te duur! Wij willen geen eenheid voor het uitwendige, ten koste onzer vrijheid; maar inwendige eenheid, zooals die uitgesproken is in het 17 de hoofstuk van het Evangelie van Johannes, zij is een band, uitnemender dan alle menschelijke verbonden, en die het meest kenbaar wordt in nood en gevaar" 34 .

In die genoemde geskrif van hom stel Goddefroy in verband met dieselfde Skrifgedeelte dat hy "achten de éénheid waarvan hier sprake is voor de nouwlettenden Bijbelleser voldoende toegelicht door het: 'één gelijk als wij' waarmede toch nimmer een uitwendige eenheid kan bedoeld zijn. De eenheid tusschen den Zoon en den Vader die in de Hemelen is, zal toch wel nooit met het uiterlijke in verband gebracht kunnen worden" 35 .

Dit was Goddefroy se wens dat die Algemene Kerkvergadering by al sy werksaamhede deur die gees en gesindheid gedra en gestuur moes 
word. Inderdaad het die handelinge op die vergadering deurentyd in die gees plaasgevind. Terwyl aan die een kant maatreëls getref is om die goeie reg van die Nederduitsch Hervormde Kerk te handhaaf, is daar aan die ander kant gewaak teen kwetsende en neerhalende verwysings na die ander kerk en is die hand van broederskap wel uitgesteek. Dat Goddefroy se koersaanduiding gevolg is, blyk ook veral baie duidelik uit die "Broederlijke schrijven" wat van die Algemene Kerkvergadering uitgegaan het aan "De Nederduitsch Hervormde of Gereformeerde Kerk, de leden der Nederduitsch Hervormde Kerk en verder aan al die weldenkende ingezeten dezer Republiek" ${ }^{36}$. In die skrywe, opgestel deur Goddefroy en deur die Algemene Kerkvergadering goedgekeur en deur al die lede onderteken, is verantwoording teenoor elkeen gedoen waar die Kerk gestaan het en waarom die Kerk wou bly voortbestaan. Kortliks het dit hierop neergekom:

"Wij zijn en blijven leden der Nederduitsch Hervormde Kerk! Wij kunnen niet anders; het is de Kerk onzer vaderen, gewaarborgd bij de Grondwet, gesteund door den Volksraad. Wij willen niemand dwingen, maar kunnen ons ook geen dwang laat welgevallen" 37 .

Hierdie besliste verklaring het hoegenaamd nie beteken dat Goddefroy en die Nederduitsch Hervormde Kerk van plan was om 'n twis op gang te sit nie. Daarom is die broederhand onmiddellik ná hierdie verklaring uitgesteek:

"Wij zijn wars van twisten. Beter is eenigheid des geloof en der liefde tusschen twee naast elkander staande kerken, wedijverende in het heerlijk streven door Paulus aangewezen (Eph 4:15) een wedstrijd voor waarheid en vrede! Laat er een einde komen, aan het krakeel, vooral ook aan den onzalige twist over de kerkelijke goederen" 38 .

Goddefroy se houding dat "den rechten van God geordineerden weg van zachtmoedigheid en vredelievendheid" 39 bewandel moes word, het dus wel die houding en gesindheid van die Algemene Kerkvergadering van 1888 geword. Self het hy in hierdie gesindheid volhard en sovér moontlik twiste met ampsdraers en lidmate van òf die Nederduitsch Hervormde of Gereformeerde Kerk òf die Gereformeerde Kerk vermy. Ook toe die twiste "veral" deur 'n onsalige koerantgeskryf in 1888-1890 opgelaai het ${ }^{40}$ en die spanning in die stryd om die kerklike eiendomme toegeneem het, het hy nie van standpunt verander nie. Volhardend en geduldig het hy volgehou om 
die Nederduitsch Hervormde Kerk met dieselfde gesindheid te besiel. Hier het niks van die negatiewe sy van Goddefroy se karakter soos sy kortgebondenheid ${ }^{41}$, na vore gekom nie, hoewel die omstandighede daarvoor gunstig was. Hy het hier getoon dat hy ook met oneindige geduld kon optree. Daarom was dit vir hom 'n groot teleurstelling toe dit duidelik geword het dat die Nederduitsch Hervormde of Gereformeerde Kerk nie gereageer het soos hy gehoop het nie. Veral in verband met twee sake het dit na vore gekom, naamlik die afwysing deur die Nederduitsch Hervormde of Gereformeerde Kerk van die amptelike uitnodiging na die opening van Algemene Kerkvergadering van 1890 van die Nederduitsch Hervormde Kerk en die verwerping deur dieselfde kerk van die voorstelle tot skikking van die eiendomskwessie.

Op die uitnodiging wat die Nederduitsch Hervormde Kerk aan die Nederduitsch Hervormde of Gereformeerde Kerk gerig het tot bywoning van die amptelike opening van die Algemene Kerkvergadering van 1890, is die volgende antwoord ontvang:

"Uw schrijven van 26 Mei 1890 is heden behandeld in de Algem Kerkvergadering der Ned Herv of Geref Kerk. Als antwoord wordt $u$ de volgende resolutie toegezonden: Aangezien het nog niet door de Ned Herv of Geref Kerk duidelijk is uitgesproken wat haar verhouding is tot de thans bestaande Herv Kerk, en het aanneemen der uitnoodiging tot de plechtige opening van de Algem Verg der bovengenoemde Herv Kerk tot verkeerde gevolgtrekkengen zal kunnen aanleiding geven, besluit deze Verg van bovengezegde uitnoodiging geen gebruik te zullen maken" ${ }^{42}$.

Diep teleurgesteld is Goddefroy se kommentaar op hierdie antwoord:

“Als dit recht is, dan kan een Christen nooit een bezoek afleggen bij een broeder tenzij eerst de verhouding waarin hij tot hem staat te voren duidelik is uitgesproken. Ook mag een Christen nooit samengaan met een ander op den weg, wanneer dit tot verkeerde gevolgtrekkingen zou aanleiding kunnen geven. Dan zou de Here Jesus geen goed exempel gegeven hebben door zijn bezoek aan Simon den Farizeër, en minder nog als Hij omringd was van zondaren en tollenaren, want daardoor hebben zijne vijanden Hem een vriend van tollenaren en zondaren genoemd en Hem uitgescholden voor een vraat en wijnzuiper" ${ }^{43}$. 
Ook die verwerping van voorstelle tot skikking van die eiendomskwessie het hom teleurgestel en hy het dit so verwoord:

"Door het weigeren van den kant der Ned Herv of Geref Kerk is de weg, in dit geval, door twee christelijke kerkgenootschappen, naar uitspraak van Gods Woord aangewezen, niet bewandeld" 44 .

Nogtans het hierdie teleurstellings hom nie laat afwyk van sy ingeslane weg om die gesindheid tussen die twee kerke te verbeter nie. Selfs nie toe van die Nederduitsch Hervormde gemeentes na die hooggeregshof moes gaan om die eiendomskwessies te beslis en hy self in die belangrike toetssaak in verband met die eiendomme te Trichartsfontein as vernaamste verteenwoordiger van die Nederduitsch Hervormde Kerk betrokke was, het hy hierin verslap nie. As die gesindheid tussen die twee kerke na die hofuitspraak van 5 Junie 1893 in die Trichardtsfontein kerksaak skerp versleg, dan word dit aanleiding daartoe dat Goddefroy in 'n beskrywingspunt die Algemene Kerkvergadering van die Nederduitsch Hervormde Kerk van 1893 vra om in gehoorsaamheid aan die Skrif te besin en uitspraak te doen oor die vraag wat die verhouding tussen mens en mens, Christen en Christen en kerkgenootskap en kerkgenootskap behoort te wees. Oor die verhouding tussen kerkgenootskap en kerkgenootskap het die vergadering onder sy leiding besluit:

"Tusschen Kerkgenootschappen en Kerkgenootschappen is de verhouding uitgedrukt in die Nederlandsche Geloofsbelijdenis art 29a.

Wij gelooven dat men wel naarstiglijk en met goede voorsigtigheid uit het Woord van God behoort te onderscheiden, welke de ware Kerk zij; aangezien dat alle zekten die hedendaags in de wereld zijn zich met de naam der Kerk bedekken. Wij spreken hier niet van het gezelschap der geveinsden, welke in de Kerk onder de goede vermengd zijn, hoewel zij naar het lichaam onder dezelve zijn, maar wij zeggen, dat men het lichaam en de gemeenschap der ware Kerk onderssheiden zal van alle zekten, welke zeggen dat zij de Kerk zijn. De merktekenen om de ware Kerk te kennen zijn deze, zoo de Kerk de reine prediking des Evangelies oefent. Zoo zij gebruikt de reine bediening der Sacramenten, gelijk Christus dezelve ingesteld heeft; zoo de kerklijke tucht gebruikt wordt om de zonden te straffen.

Kortlijk zoo men zich aanstelt naar het zuivere Woord van God, verwerpende alle dingen die daartegen zijn, houdende Christus voor het eenige hoofd. 
Tegenover alle kerken, die deze merktekenen van die ware Kerk dragen staat de Nederduitsch Hervormde Kerk, zinds de aanleg van de Zuid-Afrikaansche Republiek in broederlijke betrekking zooals nader omschreven in de wetten en bepalingen der Nederduitsch Hervormde Kerk in de Zuid-Afrikaansche Republiek en erkent deze derhalwe as zuster Kerken met welke wij gemeenschap des Geloofs, der gebeds en der liefde kunnen oefenen.

Waar eenige klove mocht bestaan, wenscht deze vergadering van harte mede te werken om een goude brug der liefde daarover heen te leggen.

Ook in deze houdt zich deze Vergadering aan het beginsel neergelegd in art 84 van de Dordtse Kerkenordening: Geene Kerk zal over andere kerken, geen dienaar over ander dienaren en geen ouderling of diaken over andere ouderlingen of diaken eenige heerschappij voeren" 45 .

Met hierdie besluit het die Algemene Kerkvergadering presies gedoen wat Goddefroy beoog het. In aansluiting by die tradisie het die Nederduitsch Hervormde Kerk nou sy standpunt oor hierdie saak verantwoord en 'n duidelike riglyn gehad in sy optrede teenoor die ander twee kerke in die Zuid-Afrikaansche Republiek. Goddefroy self het hom streng aan hierdie besluit gehou en daarna bly streef om gesindhede te verbeter. Vir hom het daar egter nooit enige twyfel bestaan dat die ander twee kerke as ware kerke erken moes word omdat hulle die merktekens van die ware kerk gedra het nie. Hy het hom selfs geërger as verkleinerend na een van die kerke verwys is. So het hy 'n ouderling $C$ Vermaas tereggewys toe laasgenoemde na die verenigde kerk as 'n "opgelapte kerk" verwys het ${ }^{46}$.

Goddefroy het ongetwyfeld 'n belangrike bydrae gelewer om onder provokerende omstandighede die tradisionele standpunt van die Nederduitsch Hervormde Kerk oor sy houding teenoor die ander twee Afrikaanse Kerke te handhaaf en te verstewig. Hy was self baie verheug toe nog tydens sy leeftyd 'n aanmerklike verbetering in die verhoudinge ingetree het. So is hy byvoorbeeld in 1916 na die Algemene Kerkvergadering van die Ned Herv of Geref Kerk afgevaardig om groete van die Algemene Kerkvergadering van die Nederduitsch Hervormde Kerk oor te bring. As hy en sy mede-afgevaardigdes terugkeer in die Algemene Kerkvergadering van die Nederduitsch Hervormde Kerk dan maak hulle met vreugde gewag daarvan dat hulle op 'n waardige wyse met agting en liefde deur die sinode van die "zusterkerk" ontvang is. Goddefroy self het gestel dat hy "klein (was) om te denken, hoe die kerk in 1888, ons niet wilde erkennen, en nu 
ons ontving als een zusterkerk. ...Er is nu vrede en liefde en verdraagzaamheid" 47 .

Hierdie berig oor die verbeterde gesindhede het die Algemene Kerkvergadering van 1916 selfs die besluit laat neem ${ }^{48}$ :

"Aan de Algemene Commissie op te dragen, dat telkens een afgevaardigde onzer kerk zal worden gezonden naar de Synodes der Zusterkerken ook in den Vrijstaat en Kaap Kolonie en Natal".

\section{SLOT}

Slegs gesien teen die agtergrond van die spanning en emosiebelaaide atmosfeer na die mislukte kerkvereniging en die daaropvolgende twiste oor eiendomme, was die besluit in 1894 oor kanselruil merkwaardig. As die totale tradisie van die Nederduitsch Hervormde Kerk in dié verband egter in aanmerking geneem word tesame met die rigtinggewende leiding van Goddefroy, dan is die besluit inderdaad net logies. Nietemin is die tradisionele standpunt van die Nederduitsch Hervormde Kerk oor hierdie saak herbevestig en dit word tot vandag deur die Kerk gehandhaaf. Kanselruil vind inderdaad met die Nederduitse Gereformeerde Kerk plaas, maar ongelukkig steeds nie met die Gereformeerde Kerke nie. Kanselruil word deur die Nederduitsch Hervormde Kerk waardeer as uitdrukking van die eenheid wat is.

\section{NOTAS:}

1 C F A Borchardt, “Die betrekkinge tussen die drie Afrikaanse Kerke 18861973”, NGTT 15/3 (1974), 181-203.

2 Borchardt, $a w, 181$.

3 Borchardt, $a w, 183$.

$4 \quad$ Notule van die Gecombineerde Algemeene Kerkvergadering der Nederduitsch Hervormde Kerk 1894, 13.

5 S P Engelbrecht. Geskiedenis van die Nederduitsch Hervornde Kerk van Afrika, Pretoria Kaapstad ${ }^{3} 1953$.

6 S J Botha, "Ortodoks as slagspreuk en liberaal as etiket", HTS 50/1\&2 (1994), 259-262.

$7 \quad$ Engelbrecht, a $w 1953,216-229$. 
8 S P Pretorius, Die kerkvereniging van 1885 - Sy aanloop en mislukking, Ongepubliseerde DD-proefskrif: Universiteit van Pretoria 1986.

9 A D Pont, S J Botha, \& J M G Storm, Gedenkalbum 1886-1986, Pretoria 1986, 86.

10 A D Pont, "Was die optrede van die konsulentsgemeente van Pretoria in 1885 'Kerkskeurend'?", HTS 33/3\&4 (1977), 27-40.

11 Engelbrecht, $a w, 1953,302$.

12 S J Botha, "Die kerkregtelike posisie van die prokurasiekommissie in die Ned Herv of Geref Kerk", HTS (1969), 106-119.

13 S P Engelbrecht, “Die Nederduitsch Hervormde Gemeente Volksrust (Wakkerstroom)", Pretoria 1941, 21-24.

14 Engelbrecht, $a w, 1953,310-314$.

15 Pretorius, $a w, 603-611$

16 Engelbrecht, $a w, 1953,320$.

17 S J Botha, “Ontleding van die kerksaak van Trichardtsfontein 1893", HTS 17/1 (1961), 1-18.

18 Engelbrecht, $a w, 1953,350$.

19 S J Botha, "Die 'vereniging' van die gemeentes onder leiding van die prokurasiekommissie met die Nederduitsch Hervormde Kerk in 1894", HTS $51 / 3$ (1995) (Moet nog verskyn).

20 Aangehaal deur Engelbrecht, $a w, 1953,351$.

21 Engelbrecht, $a w, 1953,118-123$.

22 A D Pont, "Die vestiging van die Nederduitsch Hervormde Kerk in 1853 en die eerste afskeiding van Lydenburg 1854 - Kerkregtelike implikasies”, HTS 20/3\&4 (1964), 149-161.

23 G B A Gerdener, Boustowwe vir die geschiedenis van die NederduitsGereformeerde Kerk in die Transgariep, Kaapstad 1930, 584.

24 D van der Hoff, "Eene stem uit Mooi-rivier", herdruk in HTS 18/4 (1963), 154. 
25 Gerdener, $a w, 584$.

26 Engelbrecht, $a w, 1953,93-99$.

27 Engelbrecht, $a w, 1953,122$ en 265.

28 H M Rex, Nederduitsch Hervornde Gemeente Zeerust (Marico), Krugersdorp 1971, 203-205.

29 Engelbrecht, $a w, 1941,11$.

$30 \quad$ Engelbrecht, $a w, 1953,265$.

31 Engelbrecht, $a w, 1953,155$.

32 Vergelyk oor Goddefroy, S J Botha, Ds Marié Joseph Goddefroy, Pretoria 1981 .

33 Notulen van de Algemene Kerkvergadering der Nederduitsche Hervormde Kerk $1888,4$.

$34 \quad$ Notulen $1888,87$.

35 J Goddefroy, De Kerkkwestie, niet een leer- maar een levenskwestie, 's Gravenhage $1890,67$.

$36 \quad$ Notulen $1888,99$.

$37 \quad$ Notulen $1888,97$.

38 Notulen 1888, 97-98.

$39 \quad$ Notulen $1888,98$.

40 S J Botha, "Waar lê die wortels van die 'sondige verskeurdheid' in die kontrovers Bosman-Goddefroy 1888-1890”, HTS 33/3\&4 (1977), 41-57.

41 Botha, $a w, 1981,191-184$.

42 Notulen van de Algemeene Kerkvergadering der Nederduitsch Hervormde Kerk, 1890,5 .

43 Notulen $1890,6$.

$44 \quad$ Notulen 1890.30.

45 Notulen yan de Algemeene Kerkvergadering der Nederduitsch Hervormde Kerk, 1893, 60-62. 
46 Goddefroy, $a w, 1890,59$.

47 Notulen van de Algemeene Kerkvergadering der Nederduitsch Hervormde Kerk, 1916, 19-20.

48 Notulen 1916, 20. 